\title{
К ВОПРОСУ ИССЛЕДОВАНИЯ СОСТАВА УГЛЕВОДОРОДНЫХ ГАЗОВ УГОЛЬНЫХ ПЛАСТОВ И ПЫЛИ С ЦЕЛЬЮ ВОЗМОЖНОГО ПРОГНОЗИРОВАНИЯ ИХ ПОТЕНЦИАЛЬНОЙ ОПАСНОСТИ
}

\author{
Ганова Светлана Дмитриевна', \\ ganova_s@mail.ru \\ Скопинцева Ольга Васильевна', \\ skopintseva54@mail.ru \\ Исаев Олег Николаевич', \\ isaevoleg75@mail.ru
' Российский государственный геологоразведочный университет им. Серго Орджоникидзе, Россия, 117997, г. Москва, ул. Миклухо-Маклая, 23.

\begin{abstract}
Актуальность работы обусловлена необходимостью обеспечения безопасности горных работ на высокогазоносных выбросоопасных угольных пластах, опасных по пыли. Это направление связано с исследованием всего состава газов угленосных отложений и, в частности, высших углеводородов, и оценкой их роли в возникновении взрывопожароопасных ситуаций и внезапных выбросов угля и газа в горные выработки. Определение количественного состава углеводородных газов является необходимой составляющей в процессе выявления степени выбросоопасности пластов, а также определения рациональных параметров обработки угольных пластов с целью снижения их газоносности и пылеобразующей способности для уменьшения риска возникновения пожаровзрывоопасных ситуаций в угольных шахтах.

Цель: изучить состав и количество углеводородных газов высокогазоносных выбросоопасных угольных пластов, опасных по пыли; определить интервал температур при термодегазации для полного извлечения сорбированных углеводородов; сравнить полученные данные по углеводородам углей и пыли; оценить роль сорбированных углеводородов угольной пыли в создании пылевзрывоопасных ситуаций в угольных шахтах; рассчитать количество высших углеводородов в выбросоопасных угольных пластах.

Методы: анализ отечественного и зарубежного опыта; сбор, систематизация и анализ имеющихся в литературных и фондовых источниках сведений по количеству и составу высших углеводородных газов угольных пластов; газовая хроматография с помощью хроматографа «Кристалл 5000.1》, термодегазация проб угля и угольной пыли на газовом хроматографе «М-3700», ситовый анализ фракционного состава угольной пыли; методы математической статистики для оценки достоверности полученных результатов по количеству высших углеводородных газов в угле и угольной пыли.

Результаты. Установлено, что основное количество сорбированных углеводородов выделяется из угля при термической дегазации в интервале температур 200-250 ㄷ. Содержание предельных углеводородов от метана до гексана в газах, выделенных из углей средней стадии метаморфизма и угольной пыли, составило 13,4-29,1 cм³ /кг угля, пыли. Определено обогащение десорбированных углеводородов тяжелыми углеводородами, причем в основном преобладают пропан $\left(C_{3} H_{8}\right)$ и бутан $\left(C_{4} H_{10}\right)$, выделение которых в шахтную атмосферу может привести к снижению температуры воспламенения пылегазовоздушной смеси, что представляет потенциальную опасность возникновения пожаровзрывоопасных ситуаций в угольных шахтах. Полученные данные по высшим углеводородам могут быть использованы для возможного прогнозирования степени выбросоопасности пластов.
\end{abstract}

\section{Ключевые слова:}

Угольный массив, угольная пыль, остаточные углеводороды углей и пыли, высшие углеводороды,

термическая дегазация, выбросоопасность пластов, пожаровзрывоопасность в угольных шахтах.

\section{Введение}

Анализ аварийности и травматизма на угольных шахтах России показывает, что за последние годы на высокопроизводительных шахтах России происходили катастрофические взрывы метана и угольной пыли, сопровождавшиеся экзогенными пожарами. При этом аварии носили комплексный характер, т. е. в них реализовывалось несколько опасных факторов: газ, пыль, внезапные выбросы угля и газа, пожары, тогда как в системе профилактики взрывов основной акцент сделан на метан [1-9].

Значительное количество работ [10-13] опубликовано по сорбции углеводородов в связи с определением метаноемкости углей и гидровоздействием на угольные пласты. Однако основное внимание уделяется метану, и данные по тяжелым углеводородам практически не приводятся.

В решении проблемы борьбы со взрывами метана и угольной пыли на больших глубинах выбросо- опасных пластов остаются неопределенными механизмы газодинамических явлений, генерации углеводородов угольным веществом, образования и самовоспламенения взрывоопасной среды в горных выработках. В данной статье делаются попытки найти общие признаки в генерации высших углеводородов высокогазоносными угольными пластами и внезапными выбросами угля и газа. $\mathrm{C}$ позиций наличия высших углеводородных газов в угольной пыли дается оценка роли этих газов в возникновении пожаровзрывоопасных ситуаций в угольных шахтах.

Исследование состава и количества углеводородных газов в угле и пыли высокогазоносных пластов

Как известно, ископаемые угли относятся к своеобразному классу природных сорбентов, которые получили название «молекулярных сит». Для них характерна пористая структура с преоблада- 
нием главным образом микропор диаметром 1,0-1,5 нм. Поэтому скорость свободной десорбции из угля последовательно снижается от $\mathrm{CH}_{4} \mathrm{\kappa}$ его гомологам, т. к. диаметр молекул в ряде $\mathrm{CH}_{4}-\mathrm{C}_{5} \mathrm{H}_{12}$ возрастает от 0,42 до 0,8 нм. Это объясняется двумя процессами: возрастанием энергий дисперсионного взаимодействия молекул гомологов метана с молекулами сорбента при объемном заполнении микропор и проявлением молекулярно-ситового эффекта в микропорах угля.

Высшие гомологи метана в основном начинают выделяться из угля после его измельчения и нагрева в вакууме. При вскрытии угольных пластов и снижении давления происходит последовательное выделение углеводородов из углей в соответствии с их сорбционными свойствами. Метан, как наиболее подвижный компонент, опережает другие, более тяжелые углеводороды (УВ), которые начинают выделяться после истечения из пласта основной доли метана. Этим можно объяснить, что в свободно выделяемых из углей газах наблюдаются низкие концентрации тяжелых УВ, которые остаются в угле как трудно выделяемые. Поэтому при прочих равных условиях процентное содержание высших углеводородных газов, выделяющихся в выработку или скважину, зависит от многих факторов, и в первую очередь от степени перемятости угольного массива.

В работе Е.С. Розанцева и Н.П. Таран [14] представлены результаты исследований по углям 10 шахт Кузбасса с выходом летучих веществ от 7 до $42 \%$, выполнен анализ 130 проб газа по определению состава газа, выделяющегося в скважины, пробуренные в пласты. Установлено, что на современных глубинах разработки в угольных пластах на всех стадиях метаморфизма может содержаться самое разнообразное количество высших углеводородов - от 0,0001 до $1,8 \mathrm{~cm}^{3} /$ г горючей массы. Результаты их опытов показали, что перемятые угли поглощают в 1,7 раза больше высших углеводородов, чем крепкие ненарушенные угли. Сорбционная емкость углей по отношению к высшим углеводородам увеличивается по мере уменьшения крепости, а следовательно, по мере увеличения степени тектонической препарации углей. По данным этих авторов с возрастанием выбросоопасности пласта и частоты проявления внезапных выбросов повышается и содержание в угле высших углеводородов (до $1,8 \mathrm{~m}^{3} /$ т горючей массы). Пласты, практически невыбросоопасные, содержат высших углеводородов до 0,001 $\mathrm{m}^{3}$ /т горючей массы; при содержании более $0,01 \mathrm{~m}^{3} / \mathrm{T}$ г.м. пласты опасны, а при содержании от 0,004 до 0,01 м³ ными от опасных к неопасным [14].

В рамках экологизации процессов горного производства [15-17] на кафедре техносферной безопасности Российского государственного геологоразведочного университета им. Серго Орджоникидзе были выполнены исследования состава и количества сорбированных углеводородов угольных пластов и пыли для условий шахты «Осинниковская», (уголь марки
Ж): E-1, E-5, К-1, К-5, угольная пыль пласта Е-5 [18]. На шахте отрабатываются три свиты пластов: Елбанская, Кандалепская и Полкашкинская (15 пластов угля марки «Ж⿱»). Мощность пластов в пределах от 0,8 до 3,2 м. Шахта относится к опасной по внезапным выбросам (К-1, Е-5) и горным ударам, опасной по суфлярным выделениям метана. Все пласты относятся к опасным по пыли. Выход летучих веществ изменяется от 29,5 до 36,2 \% , нижний предел взрывчатости пыли составляет от 30 до 45 г/ $\mathrm{m}^{3}$, удельное пылевыделение - от 295 до 1300 г/т.

Результаты исследований сорбированных углеводородов, извлеченных из углей и угольной пыли, представлены в таблице. Основное количество сорбированных углеводородов выделяется из угля при термической дегазации в интервале температур 200-250 ${ }^{\circ} \mathrm{C}$. При дальнейшем повышении температуры их «выход» снижается, что позволяет говорить о практически полном извлечении сорбированных углеводородов при температуре воздействия на уголь в интервале $200 . .250{ }^{\circ} \mathrm{C}$. Содержание предельных углеводородов от метана до гексана в газах, выделенных из углей средней стадии метаморфизма и угольной пыли, составило $13,4 \ldots 29,1 \mathrm{~cm}^{3} /$ кг угля, пыли. Определено обогащение десорбированных углеводородов тяжелыми углеводородами, причем в основном преобладают пропан $\left(\mathrm{C}_{3} \mathrm{H}_{8}\right)$ и бутан $\left(\mathrm{C}_{4} \mathrm{H}_{10}\right)[18]$.

Угольная пыль содержит больше углеводородов $\mathrm{C}_{4}-\mathrm{C}_{6}$ по сравнению с углеводородами, выделенными из углей $-\mathrm{C}_{3}-\mathrm{C}_{4}$. Содержание предельных углеводородов от пропана до гексана в сумме углеводородов, извлеченных из углей при термодегазации с температурой $250{ }^{\circ} \mathrm{C}$, варьирует в пределах 80-87\%, в угольной пыли доля извлеченных предельных углеводородов от пропана до гексана достигает $91 \%$.

Если сравнить две строчки по углю и по пыли пласта Е-5 (таблица), то можно видеть, что уголь содержит углеводороды преимущественно с диаметром молекул 0,632 нм, а пыль - с диаметром молекул 0,707-0,839 нм. Эти данные хорошо согласуются с данными Е.С. Розанцева и Н.П. Таран 0 наличии большого количества высших углеводородов в перемятых пачках угольных пластов при тектонической препарации угля. Все это еще требует своего объяснения, но можно предположить, что наличие большого количества высших углеводородов в перемятых пачках угольных пластов обусловлено образованием либо дополнительного количества высших углеводородов, которые этим же углем и сорбируются, либо повышением сорбционной способности угля, а в нашем случае и угольной пыли, по отношению к высшим углеводородам.

По данным таблицы количество высших углеводородов для угля пластов E- $5, \mathrm{E}-1$ и К -5 равно 13,$55 ; 25,15$ и $12,27 \mathrm{~cm}^{3} /$ кг или 0,$0135 ; 0,025$ и $0,0127 \mathrm{~m}^{3} /$ т. По предложенной Е.С. Розанцевым и Н.П. Таран оценке все три пласта относятся к выбросоопасным, так как содержат высших углеводородов более $0,01 \mathrm{~m}^{3} / \mathrm{T}$. 
Таблица. Основные свойства, количество и состав сорбированных углеводородов, извлеченных из угля и угольной пыли методом терлодегазации

Table. $\quad$ Main properties, amount and composition of sorbed hydrocarbons extracted from coal and coal dust by thermodegisation

\begin{tabular}{|c|c|c|c|c|c|c|c|c|c|c|}
\hline \multirow{2}{*}{$\begin{array}{l}\text { Вещество, параметры } \\
\text { Substance, options }\end{array}$} & \multicolumn{9}{|c|}{ Углеводороды /Hydrocarbons } & \multirow{2}{*}{$\Sigma *$} \\
\hline & $\mathrm{CH}_{4}$ & $\mathrm{C}_{2} \mathrm{H}_{6}$ & $\mathrm{C}_{2} \mathrm{H}_{4}$ & $\mathrm{C}_{3} \mathrm{H}_{8}$ & $\mathrm{C}_{3} \mathrm{H}_{6}$ & $\mathrm{C}_{4} \mathrm{H}_{10}$ & $\mathrm{C}_{4} \mathrm{H}_{8}$ & $\mathrm{C}_{5} \mathrm{H}_{12}$ & $\mathrm{C}_{6} \mathrm{H}_{14}$ & \\
\hline $\begin{array}{l}\text { Эффективный диаметр молекулы, нм } \\
\text { Effective diameter of the molecule, nm }\end{array}$ & 0,414 & 0,537 & 0,495 & 0,632 & 0,599 & 0,707 & 0,674 & 0,780 & 0,839 & - \\
\hline $\begin{array}{l}\text { Относительная молекулярная масса } \\
\text { Relative molecular weight }\end{array}$ & 16,043 & 30,070 & 28,054 & 44,097 & 42,081 & 58,124 & 56,100 & 72,147 & 86,173 & - \\
\hline $\begin{array}{l}\text { Плотность, кг/нор. } \text { м }^{3} \\
\text { Density, kg/normal m }\end{array}$ & 0,715 & 1,357 & 1,260 & 2,019 & 1,915 & 2,703 & 2,668 & 3,172 & 3,638 & - \\
\hline $\begin{array}{l}\text { Пределы взрываемости, об. \% } \\
\text { Explosive limits, vol. \% }\end{array}$ & $5,0-14,0$ & $3,2-12,5$ & $2,75-28,6$ & $2,4-9,5$ & $2,1-14,5$ & $1,9-8,4$ & $1,6-12,3$ & $1,4-7,8$ & $1,25-6,9$ & - \\
\hline $\begin{array}{l}\text { Количество адсорбированного газа } \\
\text { из угля пласта E-1, см }{ }^{3} / \text { к; } \\
\text { содержание в газовой смеси, об. \% } \\
\text { Amount of adsorbed gas from the coal } \\
\text { of the reservoir E- } 1, \mathrm{~cm}^{3} / \mathrm{kg} ; \\
\text { content in gas mixture, vol. \% }\end{array}$ & $\begin{array}{c}3,9 \\
13,4\end{array}$ & $\begin{array}{c}1,25 \\
4,3\end{array}$ & $\begin{array}{c}0,71 \\
2,4\end{array}$ & $\begin{array}{l}6,59 \\
22,7\end{array}$ & $\begin{array}{l}0,7 \\
2,4\end{array}$ & $\begin{array}{c}9,4 \\
32,4\end{array}$ & $\begin{array}{l}\text { Отсут- } \\
\text { ствуют }\end{array}$ & $\begin{array}{l}4,95 \\
17,0\end{array}$ & $\begin{array}{l}1,55 \\
5,3\end{array}$ & 29,1 \\
\hline $\begin{array}{l}\text { Количество адсорбированного газа } \\
\text { из угля пласта E-5, } \text { см }^{3} / \text { кг; } \\
\text { содержание в газовой смеси, об. \% } \\
\text { Amount of adsorbed gas from the coal } \\
\text { of the E- } 5 \text { formation, } \mathrm{cm}^{3} / \mathrm{kg} ; \\
\text { content in gas mixture, vol. \% }\end{array}$ & $\begin{array}{l}2,25 \\
14,3\end{array}$ & $\begin{array}{c}0,59 \\
3,7\end{array}$ & $\begin{array}{c}0,29 \\
1,8\end{array}$ & $\begin{array}{l}7,03 \\
44,6\end{array}$ & $\begin{array}{c}0,45 \\
2,9\end{array}$ & $\begin{array}{l}4,66 \\
29,5\end{array}$ & $\begin{array}{l}\text { Отсут- } \\
\text { ствуют }\end{array}$ & $\begin{array}{c}0,21 \\
1,3\end{array}$ & $\begin{array}{c}0,29 \\
1,8\end{array}$ & 15,8 \\
\hline $\begin{array}{l}\text { Количество адсорбированного газа } \\
\text { из угля пласта К-5, см }{ }^{3} / \text { кг; } \\
\text { содержание в газовой смеси, об. \% } \\
\text { Amount of adsorbed gas from the coal } \\
\text { of the K- } 5 \text { formation, } \mathrm{cm}^{3} / \mathrm{kg} ; \\
\text { content in gas mixture, vol. \% }\end{array}$ & $\begin{array}{l}1,13 \\
8,5\end{array}$ & $\begin{array}{c}0,37 \\
2,8\end{array}$ & $\begin{array}{c}0,25 \\
1,9\end{array}$ & $\begin{array}{l}2,94 \\
22,0\end{array}$ & $\begin{array}{l}\text { Отсут- } \\
\text { ствуют }\end{array}$ & $\begin{array}{l}4,87 \\
36,5\end{array}$ & $\begin{array}{c}0,85 \\
6,4\end{array}$ & $\begin{array}{l}2,49 \\
18,7\end{array}$ & $\begin{array}{c}0,45 \\
3,4\end{array}$ & 13,4 \\
\hline $\begin{array}{l}\text { Количество адсорбированного газа } \\
\text { из угольной пыли пласта Е- } 5, \text { см}^{3} / \text { кг; } \\
\text { содержание в газовой смеси, об. \% } \\
\text { Amount of adsorbed gas from the coal dust } \\
\text { of the E- } 5 \text { formation, } \mathrm{cm}^{3} / \mathrm{kg} \text {; } \\
\text { content in gas mixture, vol. \% }\end{array}$ & $\begin{array}{c}1,31 \\
6,7\end{array}$ & $\begin{array}{c}0,29 \\
1,5\end{array}$ & $\begin{array}{c}0,21 \\
1,1\end{array}$ & $\begin{array}{c}1,45 \\
7,4\end{array}$ & $\begin{array}{c}0,11 \\
0,6\end{array}$ & $\begin{array}{l}9,74 \\
50,0\end{array}$ & $\begin{array}{c}0,09 \\
0,5\end{array}$ & $\begin{array}{l}3,96 \\
20,3\end{array}$ & $\begin{array}{l}2,31 \\
11,9\end{array}$ & 19,5 \\
\hline $\begin{array}{l}\text { Температура самовоспламенения } \\
\text { углеводородов угля, }{ }^{\circ} \mathrm{C} \\
\text { Temperature of coal hydrocarbon self-ignition, }{ }^{\circ} \mathrm{C}\end{array}$ & 595 & 515 & 435 & 470 & 448 & 405 & 366 & 286 & 233 & - \\
\hline $\begin{array}{l}\text { Удельная теплота сгорания углеводородов угля, } \\
\text { МДж/нор. }{ }^{3} \\
\text { Specific heat of coal hydrocarbon combustion, } \\
\text { MJ/Nom. } \text { m }^{3}\end{array}$ & 39,8 & 70,3 & 87,7 & 101,2 & 118,4 & 133,4 & 152,3 & 169,3 & 187,4 & - \\
\hline
\end{tabular}

Примечание: $\Sigma^{*}-$ сумма предельных углеводородов.

Note: $\Sigma *$ is the sum of the ultimate hydrocarbons.

\section{Роль остаточных углеводородов угольной пыли в создании пожаровзрывоопасных ситуаций в угольных шахтах}

О роли остаточных углеводородов углей в создании пожаровзрывоопасных ситуаций в угольных шахтах отмечалось в [18], но о роли остаточных углеводородов угольной пыли в создании пожаровзрывоопасных ситуаций данные отсутствуют, нет и данных о наличии остаточных углеводородов в угольной пыли [19]. Потенциальная опасность остаточных углеводородов углей и угольной пыли, обогащенных тяжелыми углеводородами, определяется следующим. Известно, что температура воспламенения и концентрационные пределы взрываемости тяжелых углеводородов меньше, а теплотворная способность больше, чем у метана. Именно в этом таится потенциальная опасность остаточных углеводородов, так как тепловое воздей- ствие на уголь происходит во многих процессах отделения угля от массива и способствует выделению остаточных углеводородов в шахтную атмосферу не только из угля, но и из угольной пыли.

Данные хроматографического анализа остаточных углеводородов угольной пыли показывают, что в целом остаточные углеводороды угольной пыли наследуют остаточные углеводороды углей, из которых формируется угольная пыль. Учитывая результаты выполненных исследований остаточных углеводородов угольной пыли и данные по остаточным углеводородам углей [20], можно предположить следующую последовательность развития пожаровзрывоопасных процессов в угольных шахтах:

- выделение остаточных углеводородов из углей и образование угольной пыли в процессе добычи угля; 
- воспламенение остаточных углеводородов, выделившихся из угля, и нагревание угольной пыли;

- выделение остаточных углеводородов из угольной пыли, их воспламенение и нагрев пыли до температуры протекания процессов пиролиза угольного вещества пыли;

- пиролиз угольного вещества пыли с выделением горючих веществ;

- воспламенение выделившихся горючих веществ и разогрев твердого угольного вещества пыли;

- выгорание углеродных частиц пыли.

Вся предполагаемая последовательность процессов и приводит к возникновению пожаровзрывоопасных ситуаций в угольных шахтах.

\section{Заключение}

Высшие углеводороды наряду с метаном входят в состав газов угленосных отложений. В процессе углефикации генерируется огромное количество газов, преимущественно углеводородов. Основное внимание ученых и специалистов уделяется метану. Масштабные катастрофы в угольных шахтах за последние годы в результате взрывов пылеметановоздушных смесей показали несовершенство существующей концепции обеспечения взрывобезопасности горных работ на высокогазоносных угольных пластах и требуют фундаментальных исследований для ее усовершенствования. Нам представляется целесообразным исследование вопросов, связанных с наличием высших углеводородов в высокогазоносных пластах, опасных по пыли, внезапным выбросам, для оценки их роли в возникновении внезапных выбросов угля, породы и газа и пожаровзрывоопасных ситуаций в угольных шахтах.

\section{Выводы}

1. Основное количество сорбированных углеводородов выделяется из угля при термической де-

\section{СПИСОК ЛИТЕРАТУРЫ}

1. Yang Lei. A mixed element method for the desorption-diffusion-seepage model of gas flow in deformable coalbed methane reservoirs // Mathematical Problems in Engineering. - 2014. - № 1. - P. 1-10.

2. Safety line method for the prediction of deep coal-seam gas pressure and its application in coal mines / L. Wang, Y.-P. Cheng, P.-K. Guo, W. Li // Safety Science. - 2012. - V. 50. - № 3. - P. 523-529.

3. Coal mine methane: a review of capture and utilization practices with benefits to mining safety and to greenhouse gas reduction / C.O. Karacan, F.A. Ruiz, M. Cotè, S. Phipps // International Journal of Coal Geology. - 2011. - V. 86. - № 2. - P. 121-156.

4. Risk Analysis of Dust Explosion Scenarios Using Bayesian Networks / Z. Yuan, N. Khakzad, F. Khan, P. Amyotte // Risk Analysis. - 2015. - V. 35. - № 2. - P. 278-291.

5. Баловцев С.В. Оценка аэрологического риска аварий на выемочных участках угольных шахт, опасных по взрывам газа и пыли // Горный журнал. - 2015. - № 5. - С. 91-93.

6. Поздняков Г.А., Голоскоков Е.И., Закутский Е.Л. Проблемы и перспективы развития способа мониторинга взрывобезопасно- газации в интервале температур 200-250 ${ }^{\circ} \mathrm{C}$. При дальнейшем повышении температуры их «выход» снижается, что позволяет говорить 0 практически полном извлечении сорбированных углеводородов при температуре воздействия на уголь в интервале $200-250{ }^{\circ} \mathrm{C}$.

2. Содержание предельных углеводородов от метана до гексана в газах, выделенных из углей средней стадии метаморфизма и угольной пыли, составило 13,4-29,1 $\mathrm{cm}^{3} /$ кг угля, пыли. Определено обогащение десорбированных углеводородов тяжелыми углеводородами, причем в основном преобладают пропан $\left(\mathrm{C}_{3} \mathrm{H}_{8}\right)$ и бутан $\left(\mathrm{C}_{4} \mathrm{H}_{10}\right)$.

3. Угольная пыль содержит больше углеводородов $\mathrm{C}_{4}-\mathrm{C}_{6}$ по сравнению с углеводородами, выделенными из углей $-\mathrm{C}_{3}-\mathrm{C}_{4}$. Содержание предельных углеводородов от пропана до гексана в сумме углеводородов, извлеченных из углей при термодегазации с температурой $250{ }^{\circ} \mathrm{C}$, варьирует в пределах 80-87 \%, в угольной пыли доля извлеченных предельных углеводородов от пропана до гексана достигает $91 \%$.

4. Остаточные углеводороды угольной пыли в целом наследуют остаточные углеводороды углей, из которых формируется угольная пыль. Существенная обогащенность остаточных углеводородов углей и угольной пыли тяжелыми углеводородами и их выделение в шахтную атмосферу может привести к снижению температуры воспламенения пылегазовоздушной смеси. Это и представляет потенциальную опасность возникновения пожаровзрывоопасных ситуаций в угольных шахтах.

5. Количество высших углеводородов для угля пластов Е-5, Е-1 и К-5 равно 13,$55 ; 25,15$ и $12,27 \mathrm{~cm}^{3} /$ кг или 0,$0135 ; 0,025$ и $0,0127 \mathrm{~m}^{3} /$ т. По предложенной Е.С. Розанцевым и Н.П. Таран оценке все три пласта относятся к выбросоопасным, так как содержат высших углеводородов более $0,01 \mathrm{~m}^{3} / \mathrm{T}$.

сти горных выработок // Горная промышленность. - 2016. № 4. - C. 66-67.

7. Estimation of the effective thermal properties of cracked rock / H. Zhou, H. Liu, D. Hu, F. Zhong, F. Yang, J. Lu // European Journal of Environmental and Civil Engineering. - 2016. V. 20. - P. 954-970.

8. Fractal analysis on the fracture development of sandstone using $\mathrm{AE}$ measurement / Z.Y. Yang, T.H. Huang, Y.X. Zhoo, M.C. Tsai // Harmonising Rock Engineering and the Environment: Proc. of the $12^{\text {th }}$ ISRM International Congress on Rock Mechanics. - Florida: CRC Press, 2012. - P. 182-183.

9. Jia P., Tang C.A., Zhang Y.B. Numerical study on zonal disintegration of rock mass around deep underground openings // Harmonising Rock Engineering and the Environment: Proc. of the $12^{\text {th }}$ ISRM International Congress on Rock Mechanics. - Florida: CRC Press, 2012. - P. 179-180.

10. Васючков Ю.Ф. Формы связи метана с углем и эффективность дегазации угольных пластов // Горный журнал. - 2016. № $10 .-$ C. $82-87$. 
11. Шахтные испытания усовершенствованной технологии подземной пластовой дегазации с использованием гидроразрыва / С.В. Сластунов, Е.П. Ютяев, Е.В. Мазаник, А.П. Садов, А.В. Понизов // Уголь. - 2016. - № 11. - С. 32-37.

12. Сластунов С.В., Ермак Г.Л. Обоснование выбора и эффективная реализация способов дегазации при интенсивной отработке газоносных угольных пластов - ключевой вопрос обеспечения метанобезопасности угольных шахт // Уголь. - 2013. № 1. - C. 21-24.

13. Егорова Е.А., Коликов К.С., Мегид Х.А. Оценка проницаемости угольного пласта с учетом неоднородности в геологической структуре // Горный журнал. - 2016. -№ 6. - С. 56-59.

14. Розанцев Е.С., Таран Н.П. Исследование состава углеводородных газов угольных пластов Кузбасса с целью возможного прогнозирования их выбросоопасности // Сб. Повышение безопасности труда при добыче угля. - Кемерово, Изд-во: ВостНИИ, 1990. - С. 88-95.

15. Ганова С.Д., Клюка О.Д. Управление геоэкологической безопасностью техногенных воздействий на компоненты окружающей среды при оценке риска от экзогенных геологических процессов // Известия вузов. Геология и разведка. - 2012. № 6. - С. 60-63.

\section{Информация об авторах}

Ганова С.Д., доктор геолого-минералогических наук, заведующая кафедрой техносферной безопасности Российского государственного геологоразведочного университета им. Серго Орджоникидзе.

Скопинщева O.B., доктор технических наук, профессор Российского государственного геологоразведочного университета им. Серго Орджоникидзе.

Исаев О.Н., кандидат биологических наук, доцент Российского государственного геологоразведочного университета им. Серго Орджоникидзе.
16. Исаев О.Н. Экологизация процессов горного производства // Горный информационно-аналитический бюллетень. - 2009. № 8. - C. 330-332.

17. Strokova L.A. Methods of estimating surface settlement during driving of urban tunnels // Soil Mechanics and Foundation Engineering. - 2010. - V. 47 (3). - P. 92-95.

18. Лебедев В.С., Скопинцева О.В. Остаточные газовые компоненты угольных пластов: состав, содержание, потенциальная опасность // Горный журнал. - 2017. - № 4. - С. 84-86.

19. Исследование влияния выхода летучих веществ на взрывоопасность угольной пыли / И.Е. Колесниченко, В.Б. Артемьев, Е.А. Колесниченко, В.Г. Черечукин, Е.И. Любомищенко // Уголь. - 2016. - № 2. - С. 50-55.

20. Обоснование рациональных параметров обеспыливающей обработки угольного массива в шахтах / 0.В. Скопинцева, С.В. Иляхин, Д.И. Савельев, А.Ю. Прокопович, А.С. Вертинский // Горный журнал. - 2014. - № 5. - С. 17-19.

Поступила 28.05.2018 г. 


\title{
ON THE ISSUE OF STUDYING THE COMPOSITION OF HYDROCARBON GASES OF COALS AND DUST TO PREDICT THEIR POTENTIAL HAZARD
}

\author{
Svetlana D. Ganova', \\ ganova_s@mail.ru \\ Olga V. Skopintseva', \\ skopintseva54@mail.ru \\ Oleg N. Isaev', \\ isaevoleg75@mail.ru
Russian State Geological Prospecting University n.a. Sergo Ordzhonikidze, 23, Miklouho-Maclay street, Moscow, 117997, Russia.

The relevance of the research is caused by the need to ensure the safety of mining operations on high-gas-bearing outburst-hazardous coal seams, which are dangerous for dust. This direction is associated with the study of the entire composition of the gases of coal-bearing deposits and, in particular, of higher hydrocarbons, and assessment of their role in occurrence of explosive-fire situations and sudden releases of coal and gas in mines. Determining quantitative composition of hydrocarbon gases is a necessary component in identifying the level of outburst seams, as well as determining rational processing parameters of coal seams in order to decrease their gas content and dust-forming ability to reduce the risk of fire and explosion hazards in coal mines.

The main aim of the work is to study the composition and quantity of hydrocarbon gases of high-gas-bearing outburst-hazardous coal seams, dangerous in dust; determine the temperature range during thermal degassing for complete recovery of sorbed hydrocarbons; compare the obtained data on hydrocarbons of coal and dust; assess the role of sorbed hydrocarbon coal dust in creating dust-explosion-hazardous situations in coal mines; calculate the amount of higher hydrocarbons in outburst coal seams.

Methods: analysis of domestic and foreign experience; collection, systematization and analysis of information available in literary and stock sources on the number and composition of higher hydrocarbon gases of coal seams; gas chromatography using the "Crystal $5000.1 »$ chromatograph, thermal degassing of coal and coal dust samples on the gas chromatograph "M-3700», screen analysis of the fractional composition of coal dust; methods of mathematical statistics for assessing the reliability of the results obtained by the number of higher hydrocarbon gases in coal and coal dust.

Results. It was established that the main amount of sorbed hydrocarbons is released from coal during thermal degassing in the temperature range of $200-250^{\circ} \mathrm{C}$. The content of the ultimate hydrocarbons from methane to hexane in gases extracted from coals of the middle stage of metamorphism and coal dust amounted to $13,4-29,1 \mathrm{~cm}^{3} / \mathrm{kg}$ of coal and dust. The enrichment of desorbed hydrocarbons with heavy hydrocarbons was determined, with propane $\left(\mathrm{C}_{3} \mathrm{H}_{8}\right)$ and butane $\left(\mathrm{C}_{4} \mathrm{H}_{10}\right)$ being predominant, the release of which into the mine atmosphere can lead to decrease in the ignition temperature of the dust-air mixture, which represents a potential hazard of fire and explosion hazard in coal mines. The obtained data on higher hydrocarbons can be used to predict the degree of outburst hazard.

\section{Key words:}

Coal mass, coal dust, residual hydrocarbons of coal and dust, higher hydrocarbons, thermal degassing, outburst hazard, fire and explosion hazard in coal mines.

\section{REFERENCES}

1. Yang Lei. A mixed element method for the desorption-diffusionseepage model of gas flow in deformable coalbed methane reservoirs. Mathematical Problems in Engineering, 2014, no. 1, pp. 1-10.

2. Wang L., Cheng Y.-P., Guo P.-K., Li W. Safety line method for the prediction of deep coal-seam gas pressure and its application in coal mines. Safety Science, 2012, vol. 50, no. 3, pp. 523-529.

3. Karacan C.O., Ruiz F.A., Cotè M., Phipps S. Coal mine methane: a review of capture and utilization practices with benefits to mining safety and to greenhouse gas reduction. International Journal of Coal Geology, 2011, vol. 86, no. 2, pp. 121-156.

4. Yuan Z., Khakzad N., Khan F., Amyotte P. Risk Analysis of Dust Explosion Scenarios Using Bayesian Networks. Risk Analysis, 2015, vol. 35, no. 2. pp. 278-291.

5. Balovtsev S.V. Assessment of the upper-air risk of accidents at mining areas of coal mines that are dangerous for gas and dust explosions. Gorny Zhurnal, 2015, no. 5, pp. 91-93. In Rus.

6. Pozdnyakov G.A., Goloskokov E.I., Zakutsky E.L Problems and prospects for the development of a method of monitoring the explosion safety of mine workings. Mining, 2016, no. 4, p. 66-67. In Rus.
7. Zhou H., Liu H., Hu D., Zhong F., Yang F., Lu J. Estimation of the effective thermal properties of cracked rock. European Journal of Environmental and Civil Engineering, 2016, vol. 20, pp. 954-970.

8. Yang Z.Y., Huang T.H., Zhoo Y.X., Tsai M.C. Fractal analysis on the fracture development of sandstone using $\mathrm{AE}$ measurement. Harmonising Rock Engineering and the Environment. Proc. of the $12^{\text {th }}$ ISRM International Congress on Rock Mechanics. Florida, CRC Press, 2012. pp. 182-183.

9. Jia P., Tang C.A., Zhang Y.B. Numerical study on zonal disintegration of rock mass around deep underground openings. Harmonising Rock Engineering and the Environment. Proc. of the $12^{\text {th }}$ ISRM International Congress on Rock Mechanics. Florida, CRC Press, 2012. pp. 179-180.

10. Vasyuchkov Yu.F. The forms of communication of methane with coal and the efficiency of coal seam degassing. Gorny Zhurnal, 2016, no. 10, pp. 82-87. In Rus.

11. Slastunov S.V., Yutyaev E.P., Mazanik E.V., Sadov A.P., Ponizov A.V. Mine tests of the improved technology of underground formation degassing with the use of hydraulic fracturing. Coal, 2016, no. 11, pp. 32-37. In Rus.

12. Slastunov S.V., Ermak G.L. Justification of the choice and effective implementation of degassing methods for intensive mining of 
gas-bearing coal seams is a key issue in ensuring the methane safety of coal mines. Coal, 2013, no. 1, pp. 21-24. In Rus.

13. Egorova E.A., Kolikov K.S., Megid Kh.A. Estimation of the permeability of a coal seam with allowance for heterogeneity in the geological structure. Gorny Zhurnal, 2016, no. 6, pp. 56-59. In Rus.

14. Rosantsev E.S., Taran N.P. Investigation of the composition of hydrocarbon gases of coal seams in the Kuznetsk Basin with a view to the possible prediction of their outburst hazard. Sb. Increase of labor safety in coal, Kemerovo, 1990, pp. 88-95. In Rus.

15. Ganova S.D., Kluka O.D. Management of geoecological safety of technogenic impacts on environmental components in assessing the risk from exogenous geological processes. News of universities. Geology and exploration, 2012, no. 6, pp. 60-63. In Rus.

16. Isaev 0.N. Ecologization of mining processes. Mountain informa tion and analytical bulletin, 2009, no. 8, pp. 330-332. In Rus.
17. Strokova L.A. Methods of estimating surface settlement during driving of urban tunnels, Soil Mechanics and Foundation Engineering, 2010, vol. 47 (3), pp. 92-95.

18. Lebedev V.S., Skopintseva 0.V. Residual gas components of coal seams: composition, content, potential hazard. Gorny Zhurnal, 2017, no. 4, pp. 84-86. In Rus.

19. Kolesnichenko I.E., Artemyev V.B., Kolesnichenko E.A., Cherechukin V.G., Lyubomishchenko E.I. Investigation of the effect of volatile matter on the explosiveness of coal dust. Coal, 2016, no. 2 , pp. 50-55. In Rus.

20. Skopintseva 0.V., Ilyakhin S.V., Savelyev D.I., Prokopovich A.Yu., Vertinsky A.S. Substantiation of rational parameters of dust removal treatment of coal massif in mines. Gorny Zhurnal, 2014, no. 5, pp. 17-19. In Rus.

Received: 28 May 2018.

\section{Information about the authors}

Svetlana D. Ganova, Dr. Sc., professor, Russian State Geological Prospecting University n.a. Sergo Ordzhonikidze. Olga V. Skopintseva, Dr. Sc., professor, Russian State Geological Prospecting University n.a. Sergo Ordzhonikidze.

Oleg N. Isaev, Cand. Sc., associate professor, Russian State Geological Prospecting University n.a. Sergo Ordzhonikidze. 